\title{
CAMBIOS Y PERSISTENCIAS EN LA MENTALIDAD NOBILIARIA GALLEGA EN EL TRÁNSITO DE LA EDAD MEDIA A LA MODERNA SEGÚN LA LITERATURA TESTAMENTARIA: UN ESTUDIO COMPARATIVO
}

\author{
CARLOS CALDERÓN \\ Universidad Nacional del Comahue. República Argentina
}

\begin{abstract}
Resumen
Estudio comparado de los testamentos de don Sancho de Ulloa, conde de Monterrey (m. 1505) y Gómez Pérez de las Mariñas, capitán general de Filipinas (1593), con el objeto de mostrar continuidades y cambios en la mentalidad nobiliaria expresada en sus últimas voluntades relativas a las expresiones de religiosidad, ritos funerarios y, en especial, regímenes hereditarios y legados, considerados como elementos de continuidad y fortalecimiento del núcleo familiar.
\end{abstract}

\section{Palabras clave}

Ulloa. Mariñas. Monterrey, condes de. Filipinas. Galicia. Nobleza. Testamentos. Siglos XV-XVI.

\begin{abstract}
A study comparing the testaments of don Sancho de Ulloa, count of Monterrey (d. 1505), and Gómez Pérez de las Mariñas, capitán general of the Philippines (1593), with the aim of revealing continuity and change in the noble mentality expressed in last wills through expressions of religiosity, funerary rites, and particularly hereditary regimes and bequests, considered as elements of continuity strengthening the family nucleus.
\end{abstract}

\section{Keywords}

Ulloa. Mariñas. Monterrey, counts of. Philippines. Galicia. Nobles. Testaments. 15th-16th Centuries. 
Para el Reino de Galicia, y con objetivos que apuntan a echar algo más de luz sobre sus estructuras de parentesco, sus mecanismos de relación, sus actitudes ante la vida y la muerte, la utilización del matrimonio como forma de concentración y acrecentamiento de la propiedad señorial, sistemas de sucesión, etc., se ha estudiado la "última e postrimera boluntad" de uno de los más encumbrados integrantes de la jerarquía nobiliaria de la segunda mitad del siglo XV: don Sancho de Ulloa, conde de Monterrey, muerto en Zamora en $1505^{1}$ y la de uno de los más resueltos e intrépidos constructores del imperio de los Austria en el Lejano Oriente, Gómez Pérez das Mariñas, Gobernador y Capitán General de las Filipinas, asesinado en 1593 al intentar reprimir un motín de remeros chinos ${ }^{2}$ en ocasión de una expedición a las Molucas.

Los codicilos mencionados, separados uno de otro por un siglo aproximadamente, brindan la oportunidad de efectuar un estudio comparativo de los cambios y persistencias operados en los horizontes ideológico, político, económico y aún cultural de los integrantes del extendido estamento nobiliario, óptica metodológica que, por otra parte, posibilitará hacer extensivos los resultados a la totalidad de las categorías que conformaban a este grupo de privilegiados en la Galicia de fines de la Edad Media e inicios de la modernidad clásica.

Como paso previo es necesario efectuar una aclaración sobre los diferentes roles y niveles de fortuna de los personajes cuyas disposiciones testamentarias serán comparadas y también determinar el elemento de corte que a partir de un antes y un después posibilite efectuar las distinciones conceptuales explicativas de las persistencias y/o cambios operados.

La Casa de los Ulloa vio acrecer su influencia en Galicia como resultado del establecimiento de la dinastía bastarda de los Trastámara; medraron con éxito debido -al menos hasta la llegada de los Reyes Católicos al trono- a la práctica inexistencia de la autoridad real en el territorio; los resultados de ese proceso se materializan durante la jefatura de Sancho de Ulloa (1465-1505): titular de extensos señoríos -muchos de ellos usurpados mediante el ejercicio indiscriminado de la violencia-, poseedor de una fortuna envidiable, se encontraba sólidamente posicionado en la cúspide del entretejido feudo-vasallático que caracterizaba al Reino en la segunda mitad del siglo XV. Su testamento constituye un reflejo no sólo de su situación

\footnotetext{
${ }^{1}$ CALDERÓN, Carlos, "Mentalidad y violencia nobiliaria en la Galicia de fines de la Edad Media: el testamento de Don Sancho de Ulloa, conde de Monterrey" (1505). Anales de Estudios Clásicos y Medievales Vol. I, Neuquén, MMIV, 117-34.

${ }^{2}$ Idem “(...) mando que si me llevare Dios fuera del Reyno de Galicia (...)”. El testamento de Gómez Pérez das Mariñas, Gobernador y Capitán General de las Filipinas (Año 1592)". Cuadernos de Ultramar. Revista Americanista Núm. 4, Montevideo, 2002
} 
de predominio sino también de algunas de las circunstancias coyunturales que lo condujeron al sitio que ocupaba.

Por su parte, Gómez Pérez das Mariñas aunque pertenecía a una de las Casas de más raigambre y tradición, así lo testimonia Vasco de Aponte ${ }^{3}$, su posición dentro de la misma lo remite a un nivel intermedio, potenciando a esa clase de nobles que hicieron de la fidelitas y del servicio al rey en sus variadas empresas, el norte de sus vidas a cambio de lo cual esperaban reconocimiento social y fortuna.

En tren ya de avanzar en el análisis comparativo de los testamentos del conde de Monterrey, Sancho de Ulloa y del Gobernador y Capitán General de las Filipinas, Gómez Pérez das Mariñas ${ }^{5}$ se recurrirá a pautas que se desprenden de la propia documentación, a saber: a) consideraciones generales introductorias al texto, b) disposiciones sobre el destino del alma, c) mandas relacionadas con el descanso eterno de los restos mortales y los ritos funerarios y d) reparto de los bienes terrenales.

\section{CONSIDERACIONES GENERALES INTRODUCTORIAS AL TEXTO}

El imaginario de la sociedad europea finimedieval se encontraba todavía muy influido por las grandes mortandades típicas de la crisis del siglo XIV; "la orrible o espantosa sombra de la muerte" constituía una presencia permanente y su cíclica recurrencia bajo la forma de epidemias, condujo al conde a reflexionar sobre la brevedad y transitoriedad de la vida dado que "todos estamos sujetos a la muerte, que continuo nos amenaza y amonesta"; además, el momento del tránsito no era una lejana probabilidad dado que él mismo declara la gravedad de su estado: "sepan quantos esta carta de testamento vieren como yo (...) D. Sancho de Ulloa estando enfermo de mi persona de dolencia natural, tal cual Dios nuestro Señor plugo de me dar". Por el contrario Gómez Pérez al redactar su testamento expresa estar "sano a Dios gracias de mi cuerpo e de mi voluntad e libre entendimiento" y ante la inevitable culminación del ciclo vital, manifiesta sin temor "que en pena de la primera culpa fue establecida la muerte de los hombres" y que "ninguna deuda es mas natural que esta y la más cierta que tenemos".

Por otra parte puede apreciarse una diferencia sustancial en lo relacionado con la transmisión del patrimonio material; María del Carmen Carlé en su momento señaló que a fines de la Edad Media quienes los disfrutaban eran sólo administra-

\footnotetext{
${ }^{3}$ APONTE, Vasco de, Relación de algunas Casas y Linajes del Reino de Galicia. Editorial Nova, Buenos Aires, 1943, 62-9.

${ }^{4}$ Galicia Histórica. Colección Diplomática I, 1901, Doc. LXXVI, 324-47.

${ }^{5}$ Idem Doc., 471-89.
} 
dores de los caudales que detentaban ${ }^{6} \mathrm{y}$ así lo expresa el conde: "por que todos los bienes ansi de fortuna, como de natura, como de gracia, que neste siglo presente poseemos, no son propios, más prestados para que con ellos sirvamos", atento a lo cual "estamos soxetos e obligados a dar dellos estrecha cuenta e ansí como prestados, los avemos de tornar a los propios lugares donde los ubimos". Más sencillamente el Gobernador y Capitán General de las Filipinas ante la posible llegada de la vida eterna entiende que para beneficio de sus herederos no sólo es necesario sino también conveniente "disponer de lo que en este mundo [Dios] me encomendó que fue mucho mas de lo que yo meresco dexandolo en la orden de placer concierto".

Por lo demás ambos realizan similares exposiciones dogmáticas de fe; "creyendo como creo firmemente todo lo que cre e tiene de Santa Madre Iglesia, protestando como protesto de vivir e morir en su Santa fee católica" declama don Sancho; "creyendo como creo firmemente en la fe católica" dice Gómez Pérez das Mariñas. El tópico se mantuvo inalterable a lo largo del siglo XVI y tuvo amplia difusión, dado que el testamento del conde de Monterrey fue realizado por un escribano y el del funcionario real era resultado de su propio puño y letra.

\section{DISPOSICIONES SOBRE EL DESTINO DEL ALMA}

"Primeramente, dispone el conde, mando mi anima al mi Redentor e Salvador Jesucristo que la compro e redimio por su Santa preciosa Sangre al cual suplico por que la quiera juzgar según su misericordia”. Quizás en esos momentos don Sancho efectuó un registro de su memoria de la que con seguridad afloró con fuerza el rosario de violencias que fojas más adelante serán explicitadas con ánimo reparador; es por ello que ruega a Dios se lo juzgue "según su justicia acatando su infinito precio que le costó e no el pequeño merecimiento mio y como es image e fechura suya, y no la desformidad de mis obras e pecados de los cuales yo me acuso que por su clemencia, el me la quiera escusar e le pido perdon porque le plega de me los perdonar y colocar la mia anima en su justa gloria con los suyos siervos vien aventurados amen".

Gómez Pérez das Mariñas, más sencillamente, la ofrece a la Santísima Trinidad, encomendándola a muchos santos y mártires, invocando como abogada a la "siempre virgen Santa María Señora nuestra a quien suplico (...) interceda por mi”.

${ }^{6}$ CARLE, María del C., "La sociedad castellana del siglo XV en sus testamentos". Anuario de Estudios Medievales 18, 1988, 538-39 y 545. 


\section{MANDAS RELACIONADAS CON EL DESCANSO ETERNO DE LOS RESTOS MORTALES Y LOS RITOS FUNERARIOS}

Desde Vasco López de Ulloa la Casa se consideraba especialmente vinculada al monasterio bernardo de Santa María la Real de Sobrado, sitio en el que dispuso se levantara un enterramiento que concluidas las peripecias vitales de sus integrantes, los mantuviese unidos aún después de muertos para mayor gloria de los difuntos y de los vivos del linaje ${ }^{7}$. Don Sancho no escapó a la tradición ya que sucintamente, en cuatro renglones y medio, despachó: "mando mi cuerpo a la tierra de que fue formado y mando que si a Dios nuestro Señor le pluyere de me llevar desta presente vida que sea sepultado en el $\mathbf{M}^{\mathbf{o}}$ de Santa María de Sobrado donde están enterrados mis padres y abuelos que hayan su santa gloria".

Los reflejos sociales generados por el creciente proceso de espectacularidad de los funerales nobiliarios ${ }^{8}$, se verifican también en el conde de Ulloa, otorgándole a las ceremonias rituales de duelo una magnitud y esplendidez propias de su posición como gran señor territorial gallego: "mando que para mis obsequias sean llamados todos los fraires e clérigos que uviere en las comarcas, especialmente de Santiago y Lugo e Betanzos hasta en numero de doscientos", "los quales, el dia de mi enterramiento y los dias siguientes de ochavario digan [mill] misas por mi anima". Dispone además que se los alimente y que luego de cada comida y cena "salgan con la cruz e [digan] un responso sobre mi sepultura con las hachas encendidas". Por otra parte, las dádivas asumen proporciones similares en tanto manda "que se de en pitança e de comer a ochocientos pobres los quales sean de mis tierras".

En fin, la literalidad del texto, con cierto dejo de austeridad, trata de limitar los excesos en las ceremonias y en las manifestaciones de dolor; siendo así que "mando que en las dichas obsequias no se queme ni arda mas de doce hachas e veinte y cuatro blandones". En cuanto a la exteriorización de la congoja por el óbito, exige a sus criados y vasallos "que ninguno se haya de carpur ni mejar por mi ni traer perga", es decir que nadie se arañe, ni se mese los cabellos y barbas ${ }^{9}$. Si bien es cierto que el apego por los mendicantes no se manifestó en la elección del sepul-

\footnotetext{
7 Vasco de Aponte, Recuento de las casas antiguas del Reino de Galicia. Servicio Central de Publicacións, Consellería da Presidencia, Xunta de Galicia, Santiago de Compostela, 1986. Introducción y edición crítica con notas a cargo de Manuel C. Díaz y Díaz y otros, p. 46

${ }^{8}$ QUINTANILla RASO, Ma. Concepción, "La Nobleza", Orígenes de la monarquía hispánica. Propaganda y legitimación (ca. 1400-1520). J. M. Nieto Soria (Director). Dykynson, Madrid, 1999, 92-3.

${ }^{9}$ No se ha podido establecer el significado de "ni traer perga".
} 
cro, se los consideró necesarios mediadores: "Iten mando a los monasterios de S. Francisco e Santo Domingo de la Ciudad de Zamora porque tengan cargo que los frailes (...) rueguen a nro. señor por la salvación de mi anima".

Casi cien años después el diligente funcionario real Gómez Pérez das Mariñas en su testamento registrado en Manila el 30 de septiembre de 1592, un año antes de su muerte, mantiene como sitio de enterramiento su preferencia hacia los Santos Francisco y Domingo a lo cual debe añadirse su amor a la tierra natal. En efecto, una naturaleza adversa y desconocida, la singularidad de las experiencias que le toca vivir en el Lejano Oriente y, quizás, sus obsesivos deseos de fundar un mayorazgo, alejan su última voluntad del, en la mayoría de los casos, trillado formulismo de los testamentos. El escrutinio de su palabra devela que "si Dios nuestro Señor fuese serbido de llebarme desta presente bida en esta Ciudad de Manila mi cuerpo se deposite en el conbento de Santo Domingo della en lo alto de la capilla mayor al lado derecho del altar mayor".

En cuanto a las honras que se le tributarán dispone que su cuerpo deberá estar vestido con su "abito de Santiago y que allí esté depositado y sobre del una tumba cubierta e un paño de raso negro (...) y que las fiestas principales este paño sea de terciopelo negro"; las pompas fúnebres sobresalen por su moderación, de manera tal que ordena solamente se digan "todas las misas cantadas e reçadas que fuere posible" "e por ellas se de la limosna ordinaria". El resto de los ítems estipulan quiénes acompañarán su cuerpo el día de su funeral -el Cabildo de la Iglesia Mayor y las cofradías de la ciudad-, el número de hachas de cera que deben arder -cuatro, las misas que deberán celebrarse día a día hasta cumplir un año - una cotidiana y quinientas en ocasión del primer aniversario- y finalmente "que el día de mi entierro y de las onras se bistan doce pobres a onra de los doce apostoles de la manera que pareciere a mis albaceas".

El constructo retórico de la sacralidad litúrgica se altera y adquiere tonalidades eminentemente subjetivas y novedosas cuando reitera que "si me llevare Dios fuera del reyno de Galicia, después de gastado mi cuerpo se lleven mis huesos a Galicia y se entierren en el conbento de San Francisco de la Villa de Vivero en la capilla mayor". Sus aspiraciones de que su cuerpo descanse definitivamente en Galicia se compadecen con los episodios de su existencia, dado que manda "que si Dios me llebare en estas Islas y don Luys mi hijo [y heredero] fuere a España sin poder llebar mis huesos por no estar el cuerpo gastado o por otra causa, que dexe persona de cuydado e confiança que los aga de llebar de secreto por escusar costas y con costas o sin ellas quiero que se llieven". 


\section{REPARTO DE LOS BIENES TERRENALES}

La nueva nobleza gallega, la que se asienta sobre los despojos derivados de las guerras civiles que concluyeron con el entronizamiento de Enrique II, la que aprovecha al máximo la anarquía en que se sumió Galicia hasta el gobierno de los Reyes Católicos, convirtieron a la Casa solariega en el elemento nuclear de su pensamiento y de sus acciones; "varían los patrimonios, se relevan los hombres, cambian incluso los apellidos, pero permanece invariable la casa cuya honra se cuida celosamente (...). La Casa es de alguna manera una bandera común a la que pertenecen, cuya honra buscan, por la que se baten y a la que incluso llegan a servir gratuitamente no sólo los magnates que ostentan la jefatura y los caballeros y escuderos que se vinculan a ellos, sino todos los hombres de familia, servicio y acostamiento" 10 . Pero la formalización de la Casa sería estéril por sí misma en cuanto carece del nexo imprescindible con la base material de reproducción del linaje, concretamente con el mayorazgo.

El mayorazgo, institución en la cual los bienes patrimoniales formarán una masa única, constituye un bagaje obsoleto con vistas a la sociedad moderna, pero cumple un rol fundamental en la consolidación nobiliaria finimedieval, quién así tempranamente lo comprendió fue Vasco de Ulloa el que en 1290 dispuso que a su muerte la propiedad señorial que por diversos medios había logrado reunir se convirtiera en intangible a efectos de ser heredada por el próximo titular de la Casa "con condición que ditos beens sempre anden juntos heredados e en corporados nua soa persona"11. Este peculiar modo de configuración y expansión de la propiedad feudal implica un orden sucesorio especial basado normalmente en la primogenitura y podía concretarse por licencia real, por contrato o escritura de fundación o bajo la denominada mortis causae, o sea por medio de un testamento. A su vez el creador podía señalar el orden de sucesión conociéndose esta modalidad como mayorazgo irregular ${ }^{12}$.

Don Sancho en su testamento no debió prever nada especial sobre el tema dado que él ya disponía por herencia de dos morgados o mayorazgos. En efecto, sus padres, Lópe Sánchez e Inés de Castro, obtienen de Enrique IV el 6 de mayo de 1461 la autorización para constituir dos mayorazgos, consolidando de este modo la base económica del linaje que luego su hijo y heredero expandirá aún más ${ }^{13}$. En ese sentido el conde de Ulloa hace utilización del espacio de libertad que le brinda el

\footnotetext{
${ }^{10}$ APONTE, Vasco de, Recuento de las casas..., ob . cit., 38-40

11 Idem, 46.

${ }^{12}$ CLAVERO, Bartolomé, Mayorazgo. Propiedad feudal en Castilla (1369-1836) Siglo Veintiuno, Madrid, 1974.

${ }^{13}$ APONTE, Vasco de, Recuento de las casas..., ob. cit., 42
} 
quinto de libre disposición para el pago de innumerables mandas pías, compensatorias de los daños causados en ocasión de sus correrías y en reconocimiento de la fidelidad que le demostraron sus vasallos; el resto de sus "bienes muebles e raices e semovientes e vasallos e rentas e castillos e fortalezas e todas las cosas a mi pertenecientes" los transmite íntegros a su universal heredera "Da. Francisca de Zúñiga mi hija legítima muger de D. Fer ${ }^{\mathrm{do}}$ de Andrade con la mi vendición".

Cumplidos los formalismos propios de la cosa aceptada y más allá de las consideraciones que pudiera merecer el que una mujer sea heredera del patrimonio señorial o del destino final del linaje, están dadas todas las condiciones para que el mayorazgo de los Ulloa inicie su floreciente andadura hacia la modernidad.

En cuanto a la presencia en el codicilo de alguna manifestación sobre la autoridad regia o sobre la persona real, ésta aparece nominada en una sola oportunidad y sin precisa identificación del monarca; ello sucede cuando don Sancho enumera diversos cantidades que serán distribuidas "por Dios y por mi anima" entre las cuales se destacan "mis libranças que tengo del Rey y de la merced de por vida".

Carlos Barros en su momento denominó a estos poderosos y violentos señores territoriales "nuevos lobos de la caballería gallega"14. Sus funciones de jefes de linajes, patronos y señores constituyen el sustrato básico sobre el cual perfilaron su hegemonía en un medio reducido físicamente y donde la sobrevivencia dependía de la fuerza, de las solidaridades mutuas propias del entramado feudo-vasallático y de la violencia que pudiera generarse como acción o reacción. Así fue hasta que Isabel y Fernando decidieron intervenir en esa "comarca", como despectivamente denominaron al Reino en cierta oportunidad. El sistema impuesto garantizó al segmento altonobiliario la situación de preeminencia alcanzada; quienes lo integraban: Ulloa, Andrade, Lemos, Sotomayor, Altamira, etc., de buena o mala gana se adaptaron al orden impuesto ("saquemos buen partido y obedezcamos al rey", recomendaba el Arzobispo ante las embestidas del virrey Acuña) ${ }^{15}$, pero su sistema de valores excluía, en líneas generales, cualquier reconocimiento a los soberanos ("y todos decían a una al señor Diego de Andrada que se hiciese conde [por mano del rey] y él respondía que no quería ser conde de lo suyo, y que más quería ser buen caballero que ruin conde") ${ }^{16}$. Ese, precisamente, es el tono de la construcción discursiva testamentaria del conde de Monterrey, don Sancho de Ulloa, fallecido en 1505 poco menos que un año después de Isabel la Católica.

${ }^{14}$ BARROS, Carlos, "A morte a lanzadas da condesa de Santa Marta (1470): unha análise", en: A guerra en Galicia, Asociación Galega de Historiadores, Santiago de Compostela, 1996, 92.

${ }^{15}$ APONTE, Vasco de, Relación de..., ob. cit., 144.

${ }^{16}$ Idem, 59. 
Por el contrario el testamento de Gómez Pérez das Mariñas, a la hora de su muerte gobernante y entusiasta explorador en el Lejano Oriente, con reconocida actuación a lo largo del gobierno de Felipe II, constituye un preciso diccionario del nuevo lenguaje burocrático-estatal; de su lectura emerge la inicial y sólida constatación de una lealtad a toda prueba hacia la Corona. Sus peripecias vitales, algunas conocidas a través del documento notarial objeto de este estudio o por otras vías ${ }^{17}$, están constituidas por una meticulosa sucesión de actos que convierten a la nobilitas en sinónimo de fidelitas $^{18}$ y servicio a la autoridad monárquica.

La suya es una personalidad macerada en los nuevos comportamientos políticos, económicos y socio-culturales gestados por el incipiente y transicional Estado centralizador y constituye una síntesis de las actitudes de la nobleza ante la necesidad de acomodar sus expectativas a la dimensión que le brindaba el horizonte monárquico; en efecto su carrera supo de los favores que se obtenían en la Corte; en principio se desempeñó como Corregidor en León, para serlo a posteriori en Cartagena ("Item declaro que quando salí de España dexe un pleyto de una decima de ciertas execuciones que llebe en Cartaxena siendo corregidor (...)"); el año de 1586 lo encuentra posesionado de los cargos de Justicia Mayor, Adelantado y Capitán General del Reino de Murcia, situación a la cual alude también indirectamente en su testamento. Su amplia experiencia y probada fidelidad a la monarquía recomendaban nuevamente su designación como Corregidor, esta vez en Logroño y Calahorra.

A punto de hacerse cargo de estos puestos, en el marco de las relaciones de poder que se daban en la Corte y gracias a la amistad que lo unía con el jesuita Alonso Sánchez, logró ser nombrado por Felipe II Gobernador y Capitán General de las Filipinas en 1589.

La red multidireccional de intercambios controlados por la monarquía -colorario de una soberanía cada vez más efectiva y el positivo resultado de los procesos de adaptación de la nobleza gallega-, permiten visualizar a das Mariñas en el papel de eficaz y leal funcionario que como retribución de sus servicios a la Corona percibe una jugosa remuneración: "Iten declaro que de mis bienes libres e corridos en España y de lo que e ahorrado de mi selario en estas yslas tendre hasta cien mill pesos en oro común (...)". La recepción del estipendio a cambio de los trabajos realizados viene de la mano de un concepto totalmente novedoso en la hasta aquí pró-

\footnotetext{
${ }^{17}$ CALDERÓN, Carlos, “(...) mando que si me llevare Dios fuera del Reyno de Galicia (...)...”, ob. cit.

18 "Hidalgo. De ninguna cosa se precia tanto el hombre de bien y noble como de guardar fee y palabra y ser fiel a quien debe" (COVARRUBIAS, Sebastián de, Tesoro de la lengua castellana o española, Editorial Alta Fulla, Barcelona, 1998, 590).
} 
diga y dispendiosa mentalidad nobiliaria: el sentido de la economía y de la austeridad.

Inmerso en las tendencias epocales sumatorias de prestigio y reconocimiento social y luego de demostrar su limpieza de sangre, y por tanto la idoneidad de su linaje, peticionó con éxito la concesión de hábitos de la más apreciada orden de caballería: "yo Gómez Pérez das Mariñas caballero profeso de la Orden de Santiago (...)".

El interés por formar parte de una orden de caballería no estaba asociado exclusivamente a aquellos elementos a que se hizo alusión (valimiento, identificación social, etc.) sino que posee reminiscencias con la persistencia del concepto medieval bellator y de su inherente cultivo de las armas ${ }^{19}$. El territorio insular que Gómez Pérez debía gobernar se encontraba disputado no sólo por otras potencias coloniales europeas sino también por los imperios de China y Japón. La latente conflictividad y sus funciones de Capitán General agudizaban el perfil militar de su gestión, de modo tal que antes de partir para su destino convocó a hombres de armas a efectos de participar en la jornada; entre ellos se destacan su hijo Luis Pérez das Mariñas, "cavallero profeso de la orden de Alcantara", su sobrino Fernando de Castro y varios más unidos por lazos de consanguinidad y otro tipo de relaciones propias de la feudalidad: "Iten declaro que me e servido mucho tiempo de hidalgos e personas nobles del Reyno de Galicia los quales acostumbran a servir señores sin sueldos ni selarios no mas de aficion amor boluntad obligación basalaxe reconocimiento e parentesco e otra superioridad (...)".

El oficio de las armas, el linaje limpio y reconocido, la virtud personal y el servicio a la monarquía constituyen los requisitos esenciales -convencionales ya en la segunda mitad del siglo XVI- para una reconceptualización de la nobleza; a ellas deben añadirse los relacionados con la educación entendida como práctica intelectual estamental, la que considerada un atributo que realzaba aún más la figura del señor, convirtiéndolo, por añadidura, en potencialmente apto para asesorar al monarca. Gómez Pérez das Mariñas reivindica esta responsabilidad respecto a sus descendientes "porque mi intención es que los que ubieren de goçar de mis trabajos y servicio que (...) [he hecho] a mi rey de cuya mano (...) me a benido lo que les dexo se ocupen de ordinario a servir a sus Reyes e principes y en ello gasten sus vidas y aciendas con la obligación de cavalleros nobles e por-

${ }^{19}$ QUINTANILLA RASO, Ma. C., Idem, 79-80. La autora aclara que "en la Baja Edad Media, la idea y concepción de "defensores" se ampliaba y modificaba siendo sustituida por la de "servidores", mucho más amplia y de mayor trascendencia en sus contenidos. En su aplicación de nobleza la orientaba hacia dos objetivos fundamentales: la vinculación directa con la monarquía, y, paralelamente, la identificación con los intereses del reino". 
que para esto es necessario exercicio de virtud e discreción en la niñez y esta mejor se consigue [mediante] la profesión de las letras, quero que todos los sucesores desde binculo [-que aspiraba a fundar y del cual se hablará más adelante-] tengan especial cuidado de dar estudio (...) a lo menos dos cursos de artes a sus hijos de manera quel que ubiere de suceder haya estudiado razonablemente (...)"20.

El genuino ejercicio interpretativo del testador y su preocupación por el conocimiento y el lenguaje lo conducen a otorgarle alcance vinculante a estas disposiciones demostrando, al menos en su pensamiento, la persistencia de la tensión entre la pluma y la espada, antinomia cuya superación es ya irreversible a finales del siglo XVI.

Sin embargo existe en el testamento de Gómez Pérez das Mariñas un tema que ocupa el centro del escenario, en el desarrollo del cual consume muchas fojas -dos tercios del total-, depura y ajusta su propio lenguaje, elabora una meticulosa operatoria de dimensiones pragmáticas - casi una casuística- y que por el sistema de valores que conlleva posibilita ponderar de qué forma los reflejos sociales imperantes son generadores de conductas. La historia de la hegemonía de la nobleza en los siglos XVI, XVII y XVIII se basa en la propiedad territorial feudal garantizada jurídicamente, convertida en mayorazgo, destinada al primogénito y vinculada a una Casa o título ${ }^{21}$; ya se mencionó la importancia que la Casa tenía para el linaje entre la nobleza gallega de fines del siglo XV. Cien años después ese ascendiente se conservaba íntegro.

Emilio González López sostiene que por su madre, doña Berenguela de Haro, conocida también como de las Mariñas, Gómez Pérez poseía estados en la Rioja, de ahí su designación como Corregidor en Logroño y Calahorra ${ }^{22}$; a la luz de su extremado empeño en constituir un mayorazgo en Galicia ello parece improbable o a lo sumo, formaría parte del linaje materno en un plano secundario.

En la fundamentación de la erección del vínculo se vale de diverso tipo de argumentos entre los cuales se destacan la importancia del linaje en función del servicio a la monarquía: "por quanto la oblligación ansi por mandamiento divino y umano como por disposición de derecho todos los bivientes deven querer e procurar el acrecentamiento de vida onra y estados de sus ijos e descendientes espe-

${ }^{20}$ BOUZA, Fernando, "Servir de lejos. Imágenes y espacios del Cursus Honorum cortesano en la España de los Austria", R. Tamales, J. Fernández Conde y otros, Europa: proyecciones y percepciones históricas, Ediciones Universidad de Salamanca, 1997, 71-86.

${ }^{21}$ CLAVERO, Bartolomé, 123.

22 GONZÁleZ LÓPEZ, Emilio, La Galicia de los Austria T. I. Fundación Pedro Barrié de la Maza conde de Fenosa, La Coruña, MCMLXXX, 377-78. 
cial aquellos que descenden de noble sangre ques un gran trabaxo serviendo a Dios nuestro S. or. y a sus Reyes e principes naturales". Las prestaciones al poder instituido tienen como resultado haber "alcançado vienes temporales" y abren posibilidades "para poder dexar binculos e mayorazgos e ynstituciones perpetuas con que les quede de congrua sustentación e puedan representar memorablemente la persona e memoria de aquellos de quien hubieron principio". Luego de exponer el peligro que entraña el reparto de los bienes, dado que al hacerlo las Casas perecen "sin memoria como la ynspiriencia lo a mostrado y muestra cada día", insiste en que ello podría evitarse cuando están juntos y enteros "así para servicio de Dios nuestro Señor y de sus Reyes naturales como para defensa (...) de esta linaxe e casa".

Su voluntad de perpetuación del linaje a partir de una reconocida base material es tal que está dispuesto a crear el morgado a pesar de carecer de "facultad conforme a derecho de disponer de mis bienes fuera del tercio e quinto ni tengo facultad real para ynstituyr ni fundar mayorazgo ni bincular mis bienes". Sin embargo confía en que su hijo Luis "por el amor que me tiene (...) consentira e pasara por cualquiera gravamen e condición que le ponga e dexe sobre su legitima e con ella la acetara y recibira y aprobara mi boluntad". Como recompensa "le dexo el quinto de mis bienes que le pudiera quitar". El afan puesto en la perduración del linaje es tan fuerte que no le impide vulnerar normas éticas y aún jurídicas ${ }^{23}$ : "Iten declaro por mis hijas legítimas y de doña Ana de Sotomayor y Mendoça a doña berenguela y doña gregoria das Mariñas las quales son monjas profesas y han renunciado sus legitimas en el dho. don Luys mi hijo, digo en mi persona". El lapsus revela por sí solo el atropello cometido contra el derecho de las hijas ${ }^{24}$.

El exordio concluye con un taxativo: "después de cumplido e pagado lo contenido en este mi testamento todo lo restante de mis bienes muebles e raizes derechos e otros en todo lo que se allare al tiempo de mi muerte sean vienes avinculados por siempre jamas que no se puedan bender, partir trocar ni canbear traspasar ni prescrivir empeñar ni hipotecar" 25 .

\footnotetext{
${ }^{23}$ El tratadista Diego Pérez en sus Comentarios al Ordenamiento de Montalvo expresa que pecan mortalmente aquellos que sin causa despojan a sus hijos de su legítima (Cit. por CLAVERO, Bartolomé, p. 141

${ }^{24}$ Las herederas frustradas probablemente defendieron sus derechos dado que Pablo Pérez Costanti al exhumar y publicar el documento aclara que es "de una copia auténtica sacada en el año 1596 a instancia de Da. Berenguela y Da. Gregoria, monjas de San Payo de Santiago, e hijas de Gómez Pérez, que había sido muerto a traición por los chinos en 1593" (Galicia Histórica, ob. cit., p. 489).

25 “(...) todos ni parte dellos lo uno del otro ni darlo en dote ni arras ni en dotación proter nupcias ni darlo por qualquiera título oneroso ni lustrativo ni para alimentos ni obras pias ni redencion de captivos (...)"
} 
El imperativo de la construcción discursiva carece de un anclaje tangible al estar ausente una propiedad territorial de cualquier naturaleza sobre la que asentar el nuevo mayorazgo; por tanto una de las obligaciones de su hijo y heredero es la conformación del espacio térreo que le dé sentido a la cláusula "para cumplimiento de lo qual mando que todo lo que yo dexare en dinero e bienes muebles e semovientes se enple en propiedades e posesiones rayzes en el Reino de Galicia”.

La preferencia por su tierra natal, ya manifestada a la hora de elegir su definitiva morada, se completa con el modelo exactivo propio del feudalismo tardío de base esencialmente agraria, dado que los bienes que se adquirirán no serán "casas en ciudades ni villas sino cortixos y granxas con eredamentos y despues de una vez compradas las posseçiones rraizes no se an de poder bender trocar ni cambear salbo (...) entre los que se ubieren comprado fuera del rreino de Galicia [que] se podran trocar por otros dentro del dho. rreino e benderlos para conprar otros dentro del".

En su momento Perry Anderson definió al Estado absolutista como una formación política determinada por la disolución de la servidumbre, o sea que su carácter es netamente defensivo de los intereses nobiliarios en cuanto esa descomposición atacaba por la base sus intereses de clase, y sobredeterminada por la aparición y desarrollo de la burguesía ${ }^{26}$; en España hombres de negocios y financistas, algunos muy conocidos -Simón Ruiz de Medina del Campo, Juan Maluenda de Burgos entre muchísimos otros- participaron activamente en negocios privados y con la Corona; su cosmovisión tiñó al conjunto social en proceso de mutación, claro está que mucho menos que en otros sitios de Europa occidental. El núcleo duro del codicilo de Gómez Pérez das Mariñas, esto es el relativo a la creación de un mayorazgo que perpetúe a la Casa y a su nombre, está influido por los múltiples flujos que caracterizan a esta sociedad transicional. En efecto, al disponer que todo lo que tiene se emplee en la compra de propiedades raices en Galicia añade que "no las allando se conpren censos e juros de a catorze mill el millar si los allare de Su Magestad y sino de Consejo sobre sus propios en rentas con facultad de Su Magestad con que no sea sobre los propios de la villa de Madrid que no quiero que sobre ello se conpre ninguna cosa".

Dejando de lado la animadversión hacia el Consejo madrileño -probablemente habría recientemente incumplido alguna obligación que hubiera perjudicado a los tenedores de sus juros- llama la atención el vuelco a las actividades especulativas que se completa cuando aclara que si los censos y juros se recuperan en dinero y no se esté todavía en condiciones de adquirir las propiedades inmuebles sobre las cuales se asentaría el mayorazgo "el que los redemiere sea obligado de poner el

${ }^{26}$ ANDERSON, Perry, El Estado absolutista. Siglo Veintiuno, México, 1984, 29. 
dinero en los bancos de madrid adonde estubiere la Corte con sus Consejos y que todo el tiempo quel dinero estubiere depositado el possedor del vinculo no pueda gastar nada del principal [-es decir del capital-] por ninguna bia sino lo que licitamente rrentare estando en los bancos".

El preciosismo con que encara el tema en la búsqueda de seguridades que la fortuna trastocará, dispone además que luego de su muerte se "ara (...) ynbentario de todos mis bienes dentro del veynte dias y el dinero se deposite en un conbento de Santo Domingo y los muebles se venderan dentro de un año y se cobrara lo que se me debiere e todo se yra depositando en el dho. conbento en una caxa de tres llaves que la una tenga mi eredero y la otra el perlado del conbento y la otra la justicia mayor del pueblo".

A continuación se esmera en enhebrar un meticuloso régimen sucesorio vincular en el que claramente se establece la prelación de los varones, aún de los más lejanos, sobre las mujeres: "primeramente nombro y señalo por heredero y suceçor en el dho. vinculo a don Luys Pérez das Mariñas (...) mi hijo legitimo (...) para que lo aya e goce y herede todos los días de su vida e despues de ella su hijo mayor varon siendo legitimo abido de legitimo matrimonio". El modelo agnático se subjetiva genéricamente cuando reafirma que "el que de sus descendientes ubiere de suceder en el dho. binculo a de ser baron y no enbra".

En esa línea y ante la eventualidad de que su hijo "muriere sin hijos legitimos (...) que le sucedan en el dho. binculo" elige a "don Fernando de Castro hijo segundo de Alvaro Gonçalez mi hermano e despues del (...) barones legitimos de legitimo matrimonio para siempre excluyendo a las enbras".

Ante nuevas presunciones y conjeturas de agotamiento de la consanguinidad agnática que extiende a varios parientes debe -a su pesar- reconocer que "es condición que si faltare sucesor baron de todos los que quedan llamados a de suceder en el dho. binculo e mejora el deudo de mi linaxe mas sercano baron (...) por linea de descendencia de mi señora e madre doña Beringuela de las Mariñas y abiendo muchos en grado se prefiere al mayor".

Este vuelco a los consanguíneos cognados -es decir parientes por línea femenina- es el resultado de la rentabilización del matrimonio asimétrico efectuado en su momento por su padre, Fernando Arias de Ribadeneyra. Esta decisión de ninguna manera le resta protagonismo a los varones, dado que las mujeres transmiten los derechos pero no los poseen, sensación que se refuerza cuando ante la inevitabilidad de que una mujer herede el mayorazgo prescribe que "es condición que (...) a falta de baron como esta dho. que la tal sea obligada a casarse con descendiente de mi linaje por parte de madre (...) que pueda tener abito de Santiago sin dispensación", esto es que su sangre no posea ninguna mácula. A la vez, si hubiera muchos 
varones descendientes por línea materna que reunieran el requisito de pertenecer sin dispensación a la Orden de Santiago podrá casarse con quien quisiere siempre y cuando "quel marido con quien se casare no tenga casa que le obligue a tener otro nombre y armas de que yo dexare señalado".

Sus incursiones en el catálogo de lugares comunes de la sociedad española de la modernidad clásica y de los juristas especializados en el tema lo conduce a sostener que ninguno de los herederos varones de "don Luys mi hijo e sus hijos nietos e descendientes como otro qualquiera que ubiere de suceder en este dho. binculo" "no se puedan casar con muger que no sea limpia de toda rraza de moro judio conberso yrexe penitenciado o otra qualquiera que le pueda ser de empedimento para que sus hijos no puedan tener abitos" de caballería, ingresar en colegios o formar parte del Santo Oficio de la Inquisición. Asimismo no podrán acceder al vínculo "clero de orden sacro fraire ni monja profesos ni (...) de la compañía de Jesús", "no sólo por su estado religioso, sino también en razón de su incapacidad para contraer matrimonio y tener hijos descendientes legítimos"27. A estas inhabilidades se suma "ni onbre que sea dado por herexe e penitenciado por la Santa ynquisición ni el que naciere ciego o mudo ni el que fuere leproso del mal de San Lazaro porque mi intención es quel que subcediere en el dho. vinculo sea persona para poder serbir a Dios y su Rey" y así no podrían hacerlo.

Finalmente, una memoria sin armas ni apellidos con la que asociarla carecería del atributo de perpetuación del linaje de su fundador; atento a ello "es condición que asi el dho. don Luys mi hijo como todos los demas que ubieren de subceder en este binculo se ayan de llamar sendos barones Gomez Perez das mariñas sin ponerse don y sin quel tal pueda admitirse otro nonbre y apellido a este al principio ni al cavo del nonbre mas de asi solas Gomez Perez das Mariñas (...) e que aya de traer en sus hescudos y sellos mis armas". En síntesis, sus sucesores, al llevar su misma identificación filiatoria, serían inmediatamente distinguidos por las dotes personales que él mismo se asignaba: "y así de allí adelante en todos para que sean conocidos (...) los que procedieron como caballeros servidores de Dios y de su rey amadores de la virtud y por ello sean alabados y por el contrario los que mal procedieren sean bituperados y que esto les sea estimulo para seguir en la virtud", es decir en el camino trazado por su propia vida.

Como colofón y antes de ocuparse de algunas mandas pías y de varias instrucciones a sus albaceas, toda esta laboriosa construcción, cuyo destino final es garantizar la constitución del mayorazgo y vínculo de bienes que le otorgue sustentabi-

${ }^{27}$ Del tema y de la elaboración de fórmulas al respecto se ocuparon tratadistas como Monterroso y Melgarejo (CLAVERO, Bartolomé, ob. cit., 244, nota 63). 
lidad económica y social a la prosecución de su linaje, corre peligro de no concretarse debido a la devoción a la autoridad regia que manifiesta el Gobernador y Capitán General de las Filipinas. En efecto, luego de intentar garantizar por medio de inversiones diversas el capital destinado a la adquisición o al aumento de bienes intangibles, impidiendo que "el dinero entre en poder del poseedor del binculo", abre las puertas a que el cofre en que se guardaría el metálico sólo podría ver menguado su contenido en servicio de la monarquía. Las seguridades brindadas por la caja en el convento donde reposaren sus restos, las tres llaves necesarias para su apertura y el libro donde se asentarían las cantidades ingresadas, ceden ante el deber y la fidelitas para con la Corona.

Estima conveniente, entonces, que el tesoro sea disminuido, y aún agotado, en los siguientes casos: "El primero aviendo xornada de guerra dentro o fuera del Reyno a donde baya la persona Real o príncipe de Castilla que en tal caso abiendo el poseedor del dho. binculo de yr personalmente en la dha. xornada por mandado de su Rey o príncipe e no de otra manera podra sacar todo el dinero que ubiere en la dha. caxa e gastallo como quisiere (...)"; "El segundo caso es abiendo casamiento de la persona Real y príncipe de Castilla que si el tal poseedor fuere llamado (...) para le serbir en tal casamiento (...) podera sacar de la dha. caxa todo lo que en ella ubiere y gastara libremente como quisiere" y "El tercero caso es si tal poseedor fuere ynbiado por su Rey o príncipe con enbaxada fuera de los reynos de Castilla que en tal caso podra sacar el dinero de la caxa e gastarlo como esta dho."

El texto publicado por Pablo Pérez Costanti en 1901, hace más de cien años ya, concluye con el protocolo notarial elaborado por el escribano Jerónimo de Messa, cuyo encabezamiento reza "En la muy Noble y Siempre Leal ciudad de Manila de las yslas felipinas del Poniente; a treynta dias del mes de septiembre de mill y quis. ${ }^{\circ}$ e nobenta y dos años en presencia de los testigos aquí contenidos gomez das Mariñas Caballero profeso de la Orden de Sant. ${ }^{\circ}$ Gobernador e Capitan General en estas yslas por el Rey nuestro Señor, dio y entrego a mi el presente escrivano esta escriptura cerrada (...) la qual dicho y declaro su testamento ultima e postrimera boluntad $\mathrm{y}$ herederos nombrados y donde a de ser enterrado e questa escriptura tiene trece foxas y al cabo firmado de su nombre (...)".

Las vicisitudes pasadas por los dos primeros herederos ponen en duda la concreción del mayorazgo y vinculación de bienes que tanto alentó nuestro testador; su hijo Luis Pérez das Mariñas concluyó sus días en medio de situaciones no menos trabajosas ni trágicas que las de su progenitor. Desde muy joven participó de la actividad cortesana dado que fue paje de Felipe II; dedicado a la vida militar alcanzó una capitanía en Flandes. La limpieza de su linaje, su proximi- 
dad al monarca y sus servicios a la Corona facilitaron su acceso a la Orden de Alcántara. Llegado a las Filipinas con la hueste que acompañó al nuevo Gobernador y Capitán General encabezó campañas que garantizaron la dominación española de la isla Luzón. Luego del asesinato de su padre, ocurrido el 17 de octubre de 1593, fue nombrado Gobernador y más tarde, en 1596, Capitán General. Murió a los 55 años, en 1603, luchando contra la expansión china. No dejó descendencia reconocida.

En cuanto al segundo potencial beneficiario, Fernando de Castro, también alcanzó el Lejano Oriente con su tío; éste lo designó Almirante con el objeto de rechazar la piratería y la peligrosa expansión de los imperios colindantes. El mar le atrajo de tal modo que le dedicó toda su vida; continuó en funciones durante el gobierno de su primo hasta que en Manila conoció a Isabel Barreto, Almirante lo mismo que él y viuda de Alvaro de Mendaña, con la cual contrajo enlace. Su vida está plagada de aventuras marítimas en Asia, Oceanía y América ${ }^{28}$.

A través de los testamentos de don Sancho de Ulloa, conde de Monterrey (1505) y de Gómez Pérez das Mariñas, Gobernador y Capitán General de las Filipinas (1592), se aspiró a remarcar algunos de los cambios y continuidades producidos en el comportamiento nobiliario gallego en los campos político, económico y aún cultural en el paso de la Edad Media a la Moderna.

La nobleza es la justificación y razón de ser del aparato político estatal que -con avances y retrocesos- viene erigiéndose desde que la sociedad peninsular puede mostrar perfiles alternativos a los propios del modelo feudo-vasallático; fenómenos que -a su vez- tensionan la construcción de la hegemonía nobiliaria en el marco de la soberanía asentada en la centralización de la renta. Estas líneas intentaron reflejar el sistema de valores y los cambios de conducta de los nobles gallegos en un período fundamental, el que se extiende desde los tiempos que van desde la guerra irmandiña, las guerras civiles y la intervención de los Reyes Católicos en Galicia hasta la finalización del reinado del último gran Austria, Felipe II. En este lapso de un siglo los miembros de los linajes se acomodan a las nuevas circunstancias al tiempo que con las innovaciones producidas no desplazan el legado recibido sino que incorporan lo nuevo a lo ya dado.

Este aporte supone una ampliación del campo de indagación historiográfica a la Galicia de los siglos XV y XVI a partir de pautas metodológicas basadas en los estudios comparativos, en este caso, de dos codicilos cuya redacción está separada por un siglo aproximadamente, pautas que a partir de nuevas ponderaciones de documentos ya conocidos han posibilitado verificar en la transición a la moder-

${ }^{28}$ GONZÁLEZ LÓPEZ, Emilio, pp. 378 y 381. 
nidad la repetición de postulados de contenido semántico estable, la existencia de impulsos contrarios de conservación e innovación y lo valioso del acercamiento a las historias de vida de dos destacados nobles gallegos para el conocimiento epocal. 